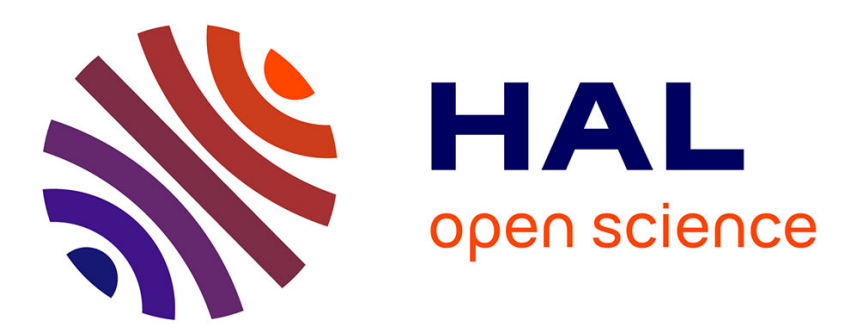

\title{
Early Stage of Growth of a Perylene Diimide Derivative Thin Film Growth on Various Si(001) Substrates
}

\author{
Matthieu Petit, Ryoma Hayakawa, Yutaka Wakayama, Toyohiro Chikyo
}

\section{To cite this version:}

Matthieu Petit, Ryoma Hayakawa, Yutaka Wakayama, Toyohiro Chikyo. Early Stage of Growth of a Perylene Diimide Derivative Thin Film Growth on Various Si(001) Substrates. Journal of Physical Chemistry A, 2007, 111 (34), pp.12747-12751. 10.1021/jp071876w . hal-01122592

\section{HAL Id: hal-01122592 \\ https://hal.science/hal-01122592}

Submitted on 4 Mar 2015

HAL is a multi-disciplinary open access archive for the deposit and dissemination of scientific research documents, whether they are published or not. The documents may come from teaching and research institutions in France or abroad, or from public or private research centers.
L'archive ouverte pluridisciplinaire HAL, est destinée au dépôt et à la diffusion de documents scientifiques de niveau recherche, publiés ou non, émanant des établissements d'enseignement et de recherche français ou étrangers, des laboratoires publics ou privés. 


\title{
Early stage of growth of a perylene diimide derivative thin film growth on various $\mathrm{Si}(001)$ substrates
}

\author{
Matthieu Petit ${ }^{a}$, Ryoma Hayakawa, Yutaka Wakayama, and Toyohiro Chikyo \\ NIMS (National Institute for Materials Science), Advanced Electronic Materials Center, 1-1 Namiki, \\ Tsukuba 305-0044 Japan
}

\section{Received:}

This study deals with the growth mode of N,N'-dipenthyl-3,4,9,10-perylenetetracarboxylic diimide (PTCDI-5C) thin films from less than one monolayer to 23 monolayers thick. The effects of growth temperature and the thickness and nature of the substrates $-\mathrm{SiO}_{2}$ on $\mathrm{Si}(001)$ or octadecyltrichlorosilane (OTS) self-assembled monolayer terminated $\mathrm{Si}(001)$ surfaces- are discussed. Thin films were deposited from a home-made Knudsen cell by using a hot-wall deposition technique. Films were analyzed by atomic force microscopy, X-ray diffraction, and X-ray reflectivity. Films exhibited a (001) orientation with a $1.63 \mathrm{~nm} d$ spacing, and a metastable thin film phase was observed without any distinction of the nature of the substrate. However, differences were noticed in the early stages of growth: PTCDI-5C/SiO 2 first monolayers presented a StranskiKrastanov growth mode, whereas PTCDI-5C/OTS first monolayers showed a more complex mode

\footnotetext{
${ }^{a}$ Corresponding author: phone +81 29851 3354, Fax: +81 29860 4796, e-mail: PETIT.Matthieu@nims.go.jp
} 
with incomplete wetting of the substrate surface. Differences between the two morphologies softened as the film thickness increased.

Keywords: Organic semiconductors, AFM, XRD, XRR

PACS : 72.80.Le, 68.55.-a, 61.10.Kw, 68.37.Ps, 68.47.Fg

\section{INTRODUCTION:}

Over the last decade organic semiconductors have been widely studied because of their potential for use in many applications: flat display panels, electronic papers, chemical sensors, etc. ${ }^{1,2}$ Although the performances of these devices are still weaker than those of inorganic semiconductors, the fabrication processes are less complex than their Si counterparts, and this is advantageous in terms of fabrication costs. In recent years, a wide range of conjugated molecules have been studied, such as pentacene, perylene, anthracene, 3,4,9,10-perylenetetracarboxylic dianhydride (PTCDA), etc. $^{3}$ The semiconducting properties of these molecules come from delocalized $\pi$-electron bondings. The $\pi$ and $\pi^{*}$ orbitals form delocalized valence and conduction wave functions supporting charge carriers. ${ }^{4}$ Thus strong dependence of the charge transport through the deposited samples is expected according to the crystalline order and crystal packing of the film. From this point of view, perylene diimides are well suitable for $n$-channel conduction since they grow in $\pi$-stacks in the bulk state. This arrangement enhances intermolecular $\pi$ orbital overlap, which is a good point for charge transport. Another requirement for optimizing charge transport is the grain size of the thin film: electron scattering at grain boundaries alters the carriers' mobility. ${ }^{5}$

Because of the electron affinity of its carboxylic parts, N,N'-dipenthyl-3,4,9,10perylenetetracarboxylic diimide (PTCDI-5C, $\mathrm{C}_{34} \mathrm{H}_{30} \mathrm{~N}_{2} \mathrm{O}_{4}$ ) is an n-channel organic semiconductor. 
PTCDI-5C thin films and transistors have been studied in recent years on different substrates. Chesterfield et al. reported the growth of PTCDI-5C on $\mathrm{Al}_{2} \mathrm{O}_{3}$ and $\mathrm{SiO}_{2} \cdot{ }^{6,7}$ In both case, the authors observed a (001) growth orientation of the PTCDI-5C, with the presence of a "thin film phase". This thin film phase, however, tends to disappear as the temperature increases and may be a metastable growth-limited phase or a thermodynamically stable polymorph. This thin film phase has also been reported in the case of pentacene thin films. ${ }^{8}$

As the orientation and morphology of molecules in the first few monolayers of the organic film work as a channel and are therefore very important in terms of OFET properties, it is crucial to have a good understanding of the growth mechanism of the first monolayers. Our study, therefore, focused on the early stages of growth of PTCDI-5C thin films on $\mathrm{Si}(001)$ substrates from less than one monolayer to 23 monolayers thick. The effects of the type of the substrates, temperature, and thickness were investigated.

\section{EXPERIMENTS:}

PTCDI-5C molecules were deposited on n-type $\mathrm{Si}(001)$ wafers by using a Knudsen cell in a vacuum organic molecular deposition system, with the base pressure below $5 \times 10^{-9}$ Torr. As the molecules evaporated quite rapidly, even at low temperatures, we used the hot wall deposition technique. ${ }^{5,9}$ Stable deposition rate and effective delivery of the molecules were thus possible, since the molecules were focused on the substrates through a heated glass tube that was set between the

crucible and substrate. A deposition rate of about 0.1 ML. $\min ^{-1}$, monitored by a quartz balance, was used and kept constant throughout all the experiments.

Two types of $\mathrm{Si}(001)$ substrate surfaces were used: surfaces terminated by $\mathrm{SiO}_{2}$ layers prepared by using Shiraki's method and surfaces terminated by self-assembly of octadecyltrichlorosilane (OTS) 
monolayers. This OTS layer was grown on silicon dioxide layers prepared by Shiraki's method. ${ }^{10}$ Substrates temperatures for growth were varied from room temperature (RT) $\left(23{ }^{\circ} \mathrm{C}\right)$ to $120{ }^{\circ} \mathrm{C}$.

The structure and morphology of the thin films were examined by atomic force microscopy (AFM SII, SPI4000). X-ray diffraction (XRD) with a Bruker D8 Discover $(\mathrm{Cu} K \alpha$ source, $\lambda=0.15418 \mathrm{~nm})$ was used to check for thin film crystallinity. X-ray reflectivity measurements were used in addition to AFM for the study of the very thin films (from 0 to 1 monolayer).

\section{RESULTS AND DISCUSSION:}

PTCDI-5C molecules crystallized into a triclinic structure, as shown in Figure 1, with the following lattice parameters ${ }^{11}: \mathrm{a}=0.4754 \mathrm{~nm}, \mathrm{~b}=0.8479, \mathrm{c}=1.6296 \mathrm{~nm}, \alpha=86.88^{\circ}, \beta=83.50^{\circ}, \gamma$ $=83.68^{\circ}$. The density was $1.36 \mathrm{~g} \cdot \mathrm{cm}^{-3}$.

\section{AFM and XRD measurements on films from 3 to 23 ML:}

The dependence on thin film structure and morphology versus type of substrate $\left(\mathrm{SiO}_{2} / \mathrm{Si}\right.$ or $\mathrm{OTS} / \mathrm{SiO}_{2} / \mathrm{Si}$ ), substrate temperature ( $\mathrm{RT}$ to $120^{\circ} \mathrm{C}$ ), and film thickness (3 to 23 monolayers; ML) were studied. AFM images are presented in Figure 2. Although no clear structure was observed in the early stages of deposition (Fig. 2a, 2e), a ribbon-like structure was clearly visible with increasing film thickness (Fig. 2b, 2f) on both the $\mathrm{SiO}_{2}$ and OTS substrates at room temperature. Here, OTS treatment resulted in an increase in ribbon size: $\sim 100 \times 400 \mathrm{~nm}$ for $\mathrm{SiO}_{2}$ to $\sim 150 \times 600 \mathrm{~nm}$ for OTS. Another effective way to increase ribbon size is to increase the substrate temperature. As temperature increased, grain growth in a lateral direction was enhanced and ribbon size increased in both types of substrate (Fig. 2b, 2f). The ribbon-like grains evolved into mesa-like grains in a 
vertical direction. In response to the combination of OTS treatment and temperature optimization, growth of grains (or ribbons) with a size of several micrometers was achieved (Fig. 2h). This size is a key point in the carriers' mobility: by increasing grain size the probability of the grain boundary altering the mobility in the channel of the transistor decreases.

Although for thicker films the morphology was the same on the two kinds of substrates at $120{ }^{\circ} \mathrm{C}$, there was a difference for the 3-ML films. Thin film grown on $\mathrm{SiO}_{2}$ at room temperature already exhibited mesa-like grains, but that on OTS presented a morphology that seemed to be more "layer by layer" oriented, with uncompleted wetting of the substrate surface. Indeed there were holes (the black parts on the pictures) where the substrate's surface appeared, as shown by the arrow in Figure 2g. The terrace heights were found to be between 1.62 and $1.75 \mathrm{~nm}$. These values almost coincided with the lattice constant of the c-axis. More details on the early stages of growth will be given in the following part.

Roughness of the surfaces was quite low and showed no significant variation with thickness or kind of substrate. Only a slight increase was noticed with increasing temperature: measured roughness varied from 1.5 to $2 \mathrm{~nm}$. The difference in morphology observed in the early stage was hidden in the thicker films.

To gain insight into the molecular orientation, we carried out XRD measurements. Figure 3 illustrates the XRD patterns of thin films grown at $120{ }^{\circ} \mathrm{C}$ with the thickness of $23 \mathrm{ML}^{\circ} \mathrm{SiO}_{2}$ at a logarithm scale. The XRD pattern on OTS was essentially the same. The pattern shows a primary peak with a $d$ spacing of $1.63 \mathrm{~nm}$. This peak is close to the (001) peak of the powder pattern $(d$ spacing $1.62 \mathrm{~nm}$ ). The FWHM of the rocking curve of the (001) peak is $0.09^{\circ} \pm 0.01^{\circ}$ (substrate $\left.\operatorname{Si}(004): 0.04^{\circ}\right)$. Smaller peaks are also clearly visible, consistent with higher orders of reflection: (002), (004), and (005). We should emphasize that the 1.63-nm $d$ spacing was close to the previous 
terrace heights found with the AFM measurements. Clearly visible and well defined fringes can be observed around the (001) peak, confirming the smoothness of the surfaces already observed from the roughness of the AFM images. Thus molecules were oriented with the c-axis normal to the surface of the substrate. This means that the $\pi$-stacking direction of the PTCDI-5C was parallel to the surface. This corresponded to the best packing scheme of the molecules from the charge transport point of view in an OFET heterostructure.

The XRD pattern in the inset corresponded to that of thin films grown at room temperature. It revealed a second set of $(00 l)$ peaks named $\left(00 l^{\prime}\right)$. The $\left(001^{\prime}\right)$ peak corresponded to a $1.83 \mathrm{~nm} d$ spacing. These observations are in agreement with previous reports. ${ }^{3,6-8}$ These $\left(00 l^{\prime}\right)$ peaks were attributed to a metastable thin film phase. The intensities of the $\left(00 l^{\prime}\right)$ peaks for $\mathrm{SiO}_{2}$ and OTS substrates decreased as growth temperature increased. The thin film phase disappeared at higher temperatures. At $120^{\circ} \mathrm{C}$, the $\left(00 l^{\prime}\right)$ peak disappeared for both substrates.

From this AFM and XRD information, on the basis of the $d$ spacing of the film it was possible to draw a scheme of the packing of the PTCDI-5C molecules on the surface of the sample. The schemes are shown in Figure 4. According to the bulk structure (Fig. 1), molecules were tilted to the (001) plan. The plan normal to the one of the aromatic cores (drawn in gray dashed lines in Fig. 4) and containing the alkyl chains was tilted from $41.9^{\circ}$ to the (001) plan. The resulting $d$ spacing was $1.63 \mathrm{~nm}$. Regarding the thin film phase, the $d$ spacing was $1.83 \mathrm{~nm}$, which means that the orientation of the molecules was different from that of the bulk. So as to satisfy this $d$ spacing value, the tilted angle had to increase from $41.9^{\circ}$ to $49.6^{\circ}$.

PTCDI-5C thin films seem to provide better characteristics at high growth temperature (wide grain size and single phase) for the purpose of fabricating an OFET. Another important factor for OFET is the orientation and morphology of the molecules in the first few monolayers. This is because the first 
few monolayers work as a channel for the OFET. In the following part, we discuss the growth mode of the early stage of thin film growth.

\section{Early stages of PTCDI-5C growth: AFM and XRR measurements}

We examined the formation of the first monolayer of PTCDI-5C on both $\mathrm{SiO}_{2}$ and OTS substrates at a growth temperature of $120^{\circ} \mathrm{C}$. AFM images are presented in Figure 5.

Images $5 \mathrm{a}$ and $5 \mathrm{~b}$ show the creation of the first PTCDI-5C monolayer on $\mathrm{SiO}_{2}$ with surface coverages of 0.40 ML and 0.90 ML, respectively. The organic layer formed wide islands-larger than one micrometer-on the surface that grew until the whole surface was covered by one monolayer.

In addition to the AFM observations, X-ray reflectivity experiments (Fig. 5c) were done on the samples. The reflectivity curves of the $\mathrm{SiO}_{2} / \mathrm{Si}$ and $\mathrm{OTS} / \mathrm{SiO}_{2} / \mathrm{Si}$ substrates are given for comparison. Parameters used to fit the curves are presented in Table 1. Parameters determined for the substrates were then kept constant for the fitting of the samples with deposited organic thin film. Fit results of the X-ray reflectivity curves of the $\mathrm{SiO}_{2} / \mathrm{Si}$ substrates provided a thickness of the PTCDI-5C layer in the range of $1.65-1.80 \mathrm{~nm}$, in agreement with previous XRD and AFM measurements. We noticed that the densities of the organic layer were lower than the PTCDI-5C nominal one ${ }^{3}\left(1.36{\mathrm{~g} . \mathrm{cm}^{-3}}^{-3}\right.$. The fitted densities increased from 0.80 g.cm ${ }^{-3}$ to 1.33 g. $\mathrm{cm}^{-3}$ as the coverage rate of the organic layer increased from 0.40 to $0.90 \mathrm{ML}$. These densities lower than the nominal value take into account the fact that the monolayer was not complete. Moreover, from these fittings, it seems that the density of the monolayers was close to the bulk value.

The growth mode of this first PTCDI-5C monolayer on the $\mathrm{SiO}_{2}$ surface was two-dimensional. Looking at Figures 5a, 5b, and 2c together, we can conclude that PTCDI-5C molecules grow in a 
Stransky-Krastanov mode. That is, a wetting layer one monolayer thick is formed first and then subsequent monolayers are stacked up, forming a mesa structure a few layers thick.

Images of the first monolayer of PTCDI-5C on OTS/SiO $2 / S i$ substrate are illustrated in Figure $5 \mathrm{~d}-$ 5e. The growth mode on this substrate was obviously different from that on $\mathrm{SiO}_{2} / \mathrm{Si}$ substrate. First, smaller islands were grown on OTS than on the $\mathrm{SiO}_{2} / \mathrm{Si}$ substrates: the average size was about 250 $\mathrm{nm}^{2}$ (Fig. 5d). This result suggests that the probability of nucleation on OTS was higher than that on $\mathrm{SiO}_{2}$. As the deposition time increased, the islands coalesced and a second monolayer started to grow: parts of the surface were covered by islands of two monolayers high (coverage rate $45 \%$ ) and other parts by only one monolayer (Fig. 5e, arrow) (coverage rate 6\%), the substrate surface remaining incompletely wet.

X-ray reflectivity curves of PTCDI-5C on OTS/SiO $2 / \mathrm{Si}$ substrates are also shown in Figure 5f. The reflectivity curve for the $\mathrm{OTS} / \mathrm{SiO}_{2} / \mathrm{Si}$ substrates was fitted according to the literature: ${ }^{12,13}$ the $\mathrm{Si}$ (001) substrate was first covered by a silicon dioxide layer (thickness $\sim 2.30 \mathrm{~nm}$ ). We noted that since the indices of refraction of silicon and silicon dioxide are very close, the fits were not very sensitive to a change in this silicon dioxide layer. To fit the OTS monolayer, the OTS molecule was divided into two "virtual layers" to take into account the difference in density between the silane head and the alkyl chain. The first "virtual layer" corresponded to the silane head. The thickness was close to the Si-O-Si bond length and the density was between that of the silicon dioxide layer and that of the OTS. Actually, this first "virtual layer" can be seen as the interface between the silicon dioxide layer and the alkyl chains of the OTS molecules. Eventually the second "virtual layer" corresponds to the alkyl chain of the OTS layer. The thickness was fixed to $2.3 \pm 0.1 \mathrm{~nm}$.

The fitting parameters for the thickness $\mathrm{d}_{1}$, corresponding to the lowest coverage rate of 0.36 , gave a thickness of $1.66 \mathrm{~nm}$ and a density of $0.73 \mathrm{~g} . \mathrm{cm}^{-3}$. For longer deposition times, the fitted thicknesses were between the height of one and two monolayers: $2.70 \mathrm{~nm}$ for $\mathrm{d}_{2}$ and $2.80 \mathrm{~nm}$ for $\mathrm{d}_{3}$ 
which renders the fact that the surface cover was a mixture of one and two monolayers, as observed with AFM. For the same purpose, we chose to allow a linear gradient to fit the density. The first number is the bottom density of the layer and the second is the top density. The values of fitted thicknesses and densities confirmed our observations made by AFM. As the deposition time increased, the surface was first covered by islands one monolayer high. The islands then grew in both lateral and vertical directions up to two monolayers.

Figure 6 summarized the two different growth processes on $\mathrm{SiO}_{2}$ and OTS substrates. In the case of PTCDI-5C on $\mathrm{SiO}_{2}$, the first monolayer exhibited a two dimensional growth. Subsequent monolayers formed mesa structures. Regarding the growth of PTCDI-5C on OTS, islands that coalesced formed.

From these results and the previous ones in Figure 2, OTS surface treatment was found to affect the lateral diffusion and adsorption of PTCDI-5C. The surface covered by the OTS monolayer had the same nature as a $\mathrm{SiO}_{2}$ surface covered by the first monolayer of PTCDI-5C, in the case of the Stransky-Krastanov growth of PTCDI-5C/SiO 2 . (In terms of surface energy, a surface such as OTS SAM that is terminated by alkyl chains exhibits a lower surface energy than a $\mathrm{SiO}_{2}$ surface: $\sigma_{\text {OTS }}=$

$\left.20 \mathrm{~mJ} . \mathrm{m}^{-2}, \sigma_{\mathrm{SiO}_{2}}=78 \mathrm{~mJ} \cdot \mathrm{m}^{-2}{ }^{14,15}\right)$. That is to say, OTS/SiO 2 and $1 \mathrm{~L}$ of PTCDI-5C/SiO 2 surfaces are terminated by alkyl chains. Thus the growth mode of PTCDI-5C on OTS was similar to the growth mode of PTCDI-5C on the first PTCDI-5C monolayer deposited on $\mathrm{SiO}_{2}$.

\section{CONCLUSION:}

We studied the effects of the substrate temperature and thickness and the nature of the surface substrate on the growth of PTCDI-5C thin films. Thin films with thicknesses ranging from less than one monolayer to 23 monolayers were grown. Both thin films grown on $\mathrm{SiO}_{2}$ or OTS substrates 
exhibited a (001) orientation. Thus the $\pi$ stacking occurred parallel to the substrate surface. However, a thin film phase with a $d$ spacing of $1.83 \mathrm{~nm}$ was observed. This phase disappeared as the growth temperature increased.

There were some differences at the early stage of growth. In PTCDI-5C/SiO 2 the first three monolayers presented a Stransky-Krastanov growth mode. During the growth of the first three monolayers in PTCDI-5C/OTS there was incomplete wetting of the surface and the beginning of a 3D growth mode. These differences can be explained in terms of molecule-substrate interactions at

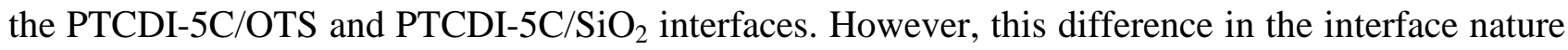
was effective only for first monolayers; thin films grown on $\mathrm{SiO}_{2}$ and OTS substrates had the same morphology at higher thickness.

${ }^{1}$ C.D. Dimitrakopoulos, P.R.L. Malenfant, Adv. Mater., vol. 14, Issue 2, 2002, 99-117

${ }^{2}$ G. Horowitz, J. Mater. Res., vol. 19, No. 7, 2004, 1946-1962

${ }^{3}$ F. Schreiber, Phys. Stat. Sol. (a) 201, No. 6, 1037-1054 (2004)

${ }^{4}$ R. H. Friend, R. W. Gymer, A. B. Holmes, J. H. Burroughes, R. N. Marks, C. Taliani, D. D. C. Bradley, D. A. Dos Santos, J. L. Bredas, M. Logdlund, W. R. Salaneck, Nature 397, 121-128 (1999)

${ }^{5}$ H. Sasaki, Y. Wakayama, T. Chikyow, E. Barrena, H. Dosch, K. Kobayashi, Appl. Phys. Lett. 88, 081907 (2006)

${ }^{6}$ R. J. Chesterfield, J. C. McKeen, C. R. Newman, P. C. Ewbank, D. A. da Silva Filho, J.-L. Bredas, L. L. Miller, K. R. Mann, C. D. Frisbie, J. Phys. Chem. B.; 2004; 108(50); 19281-19292 
${ }^{7}$ R. J. Chesterfield, J. C. McKeen, C. R. Newman, C. D. Frisbie, P. C. Ewbank, K. R. Mann, L. L. Miller, J. Appl. Phys., 2004, vol. 95, Issue 11, pp. 6396-6405

${ }^{8}$ D. J. Gundlach, T. N. Jackson, D. G. Schlom, S. F. Nelson, Appl. Phys. Lett., 74, Issue 22, pp. 3302-3304 (1999)

${ }^{9}$ H. Sasaki, Y. Wakayama, T. Chikyow, M. Imamura, A. Tanaka, K. Kobayashi, Solid State Commun., Volume 139, Issue 4, 2006, pp 153-156

${ }^{10}$ Y. Wang. M. Lieberman, Langmuir 19 (2003) 1159-1167

${ }^{11}$ E. Hädicke, F. Graser, Acta Cryst. (1986). C42, 189-195

${ }^{12}$ A.G. Richter, C.-J. Yu, A. Datta, J. Kmetko, P. Dutta, Phys. Rev. E 61, 607-615 (2000)
${ }^{13}$ A. Baptiste, A. Gibaud, J. F. Bardeau, K. Wen, R. Maoz, J. Sagiv, B. M. Ocko, Langmuir 18(10) (2002) 3916-3922

${ }^{14}$ D. Vuillaume, C. Boulas, J. Collet, G. Allan, C. Delerue, Phys. Rev. B 58, 16491 (1998)

${ }^{15}$ J. Collet, O. Tharaud, A. Chapoton, D. Vuillaume, Appl. Phys. Lett. 76, 1941 (2000) 

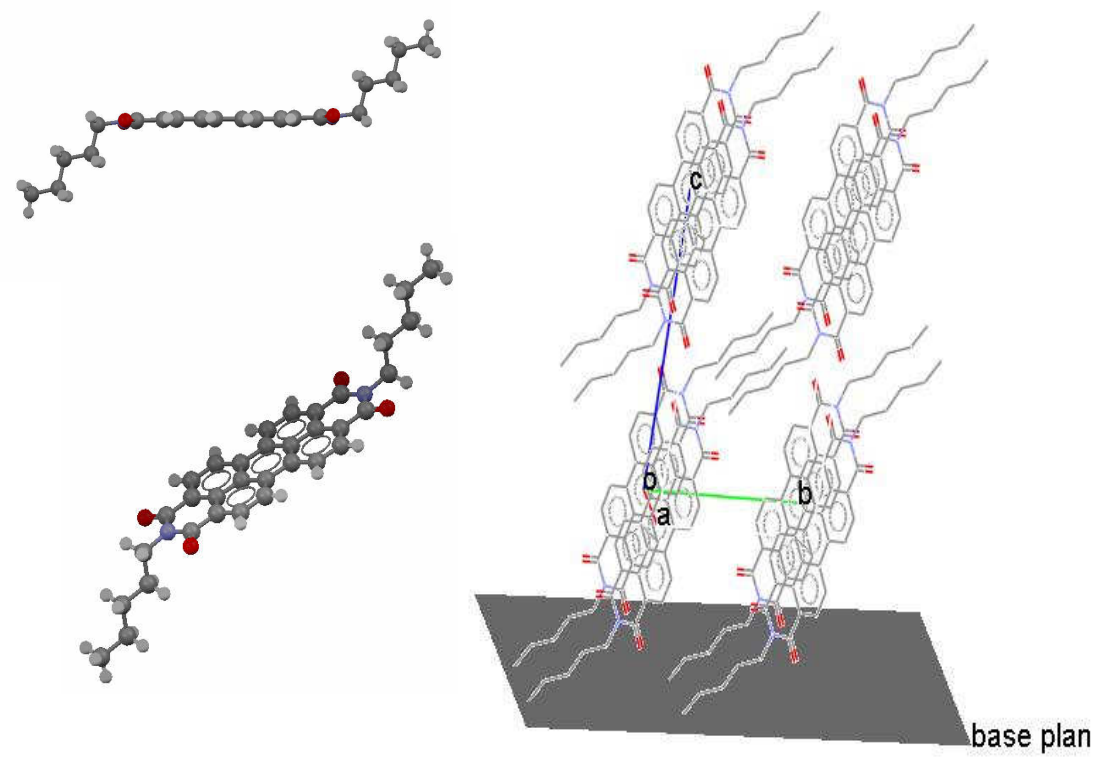

Figure 1: Crystal structure of the bulk molecules. The base plan is parallel to the (001) plan. 

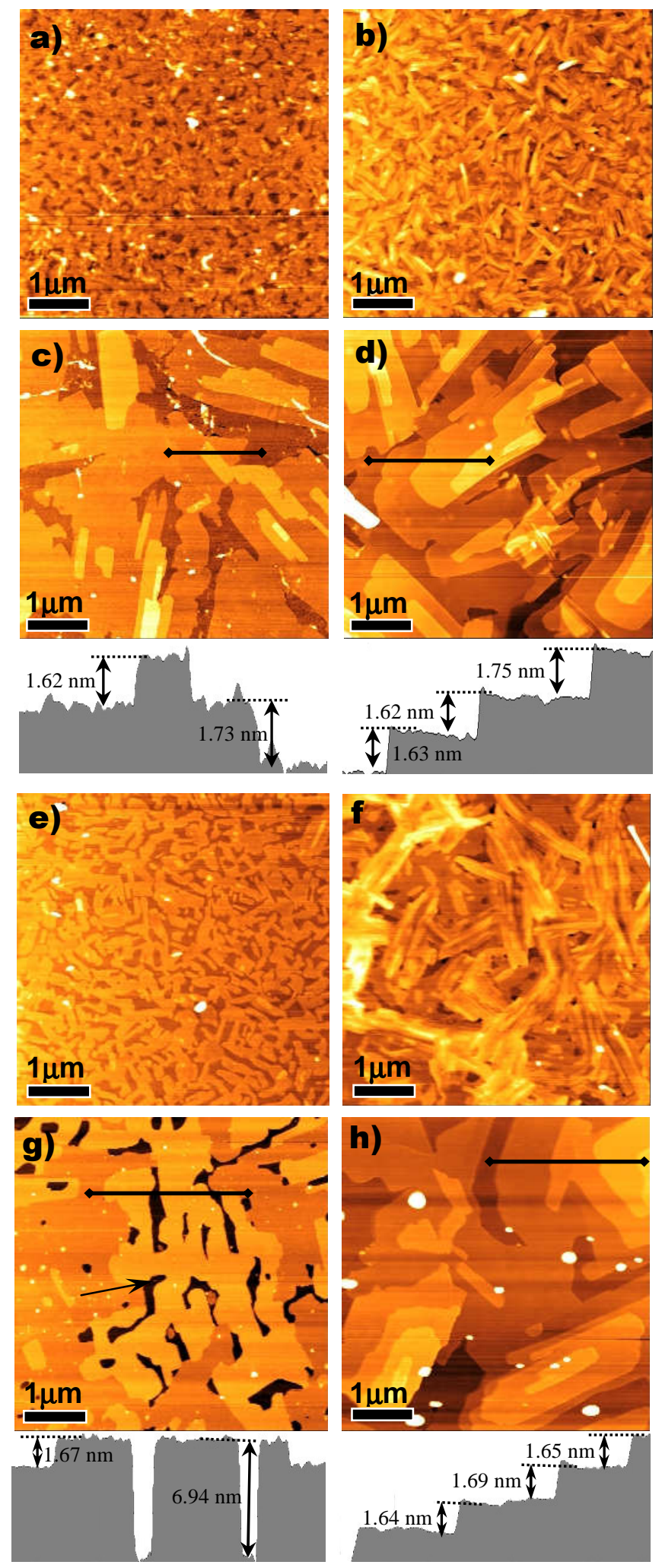

Figure 2: a)-d) $5 \times 5 \mu^{2}$ AFM images of PTCDI-5C thin films deposited on $\mathrm{SiO}_{2} / \mathrm{Si}$ substrates at two different thickness and temperatures. a) RT, $3 \mathrm{ML}$; b) RT, $23 \mathrm{ML}$; c) $120{ }^{\circ} \mathrm{C}, 3 \mathrm{ML}$ with 
corresponding profile; d) $120^{\circ} \mathrm{C}, 23 \mathrm{ML}$ with corresponding profile. e)-h) $5 \times 5 \mu \mathrm{m}^{2}$ AFM images of PTCDI-5C thin films deposited on OTS/Si substrates at two different thicknesses and temperatures. e) RT, $3 \mathrm{ML}$; f) RT, $23 \mathrm{ML}$; g) $120{ }^{\circ} \mathrm{C}, 3 \mathrm{ML}$ with corresponding profile; h) $120{ }^{\circ} \mathrm{C}$, 23ML with corresponding profile. 


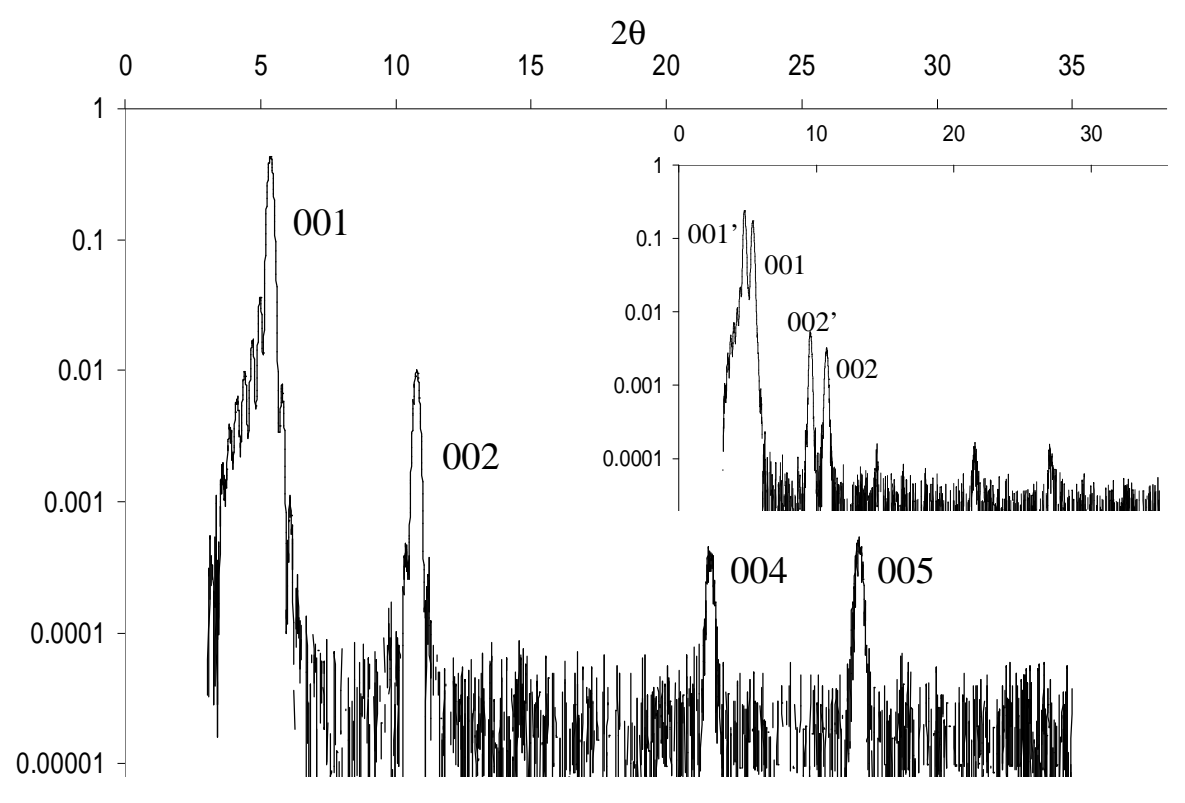

Figure 3: $\theta-2 \theta$ x-ray diffraction scan of PTCDI-5C thin film deposited at $120{ }^{\circ} \mathrm{C}$ for both $\mathrm{SiO}_{2}$ and OTS substrates. Inset: $\theta-2 \theta$ x-ray diffraction scan of PTCDI-5C thin film deposited at room temperature. Peaks labeled $(00 l)$ correspond to the spacing observed in bulk PTCDI-5C; those labeled ( $\left.00 l^{\prime}\right)$ correspond to elongated (001) interplanar spacings attributed to the thin film phase. 


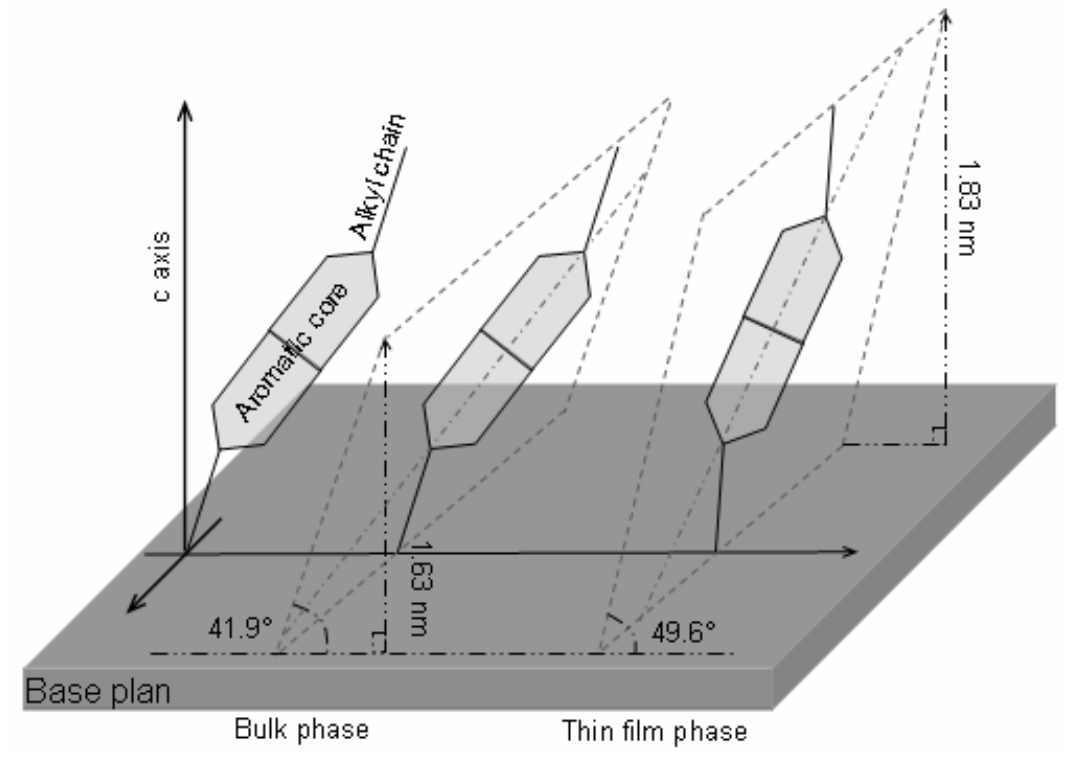

Figure 4: Illustration of molecule packing for the bulk ( $d$ spacing $1.63 \mathrm{~nm})$ and thin film $(d$ spacing $1.83 \mathrm{~nm}$ ) phases. 

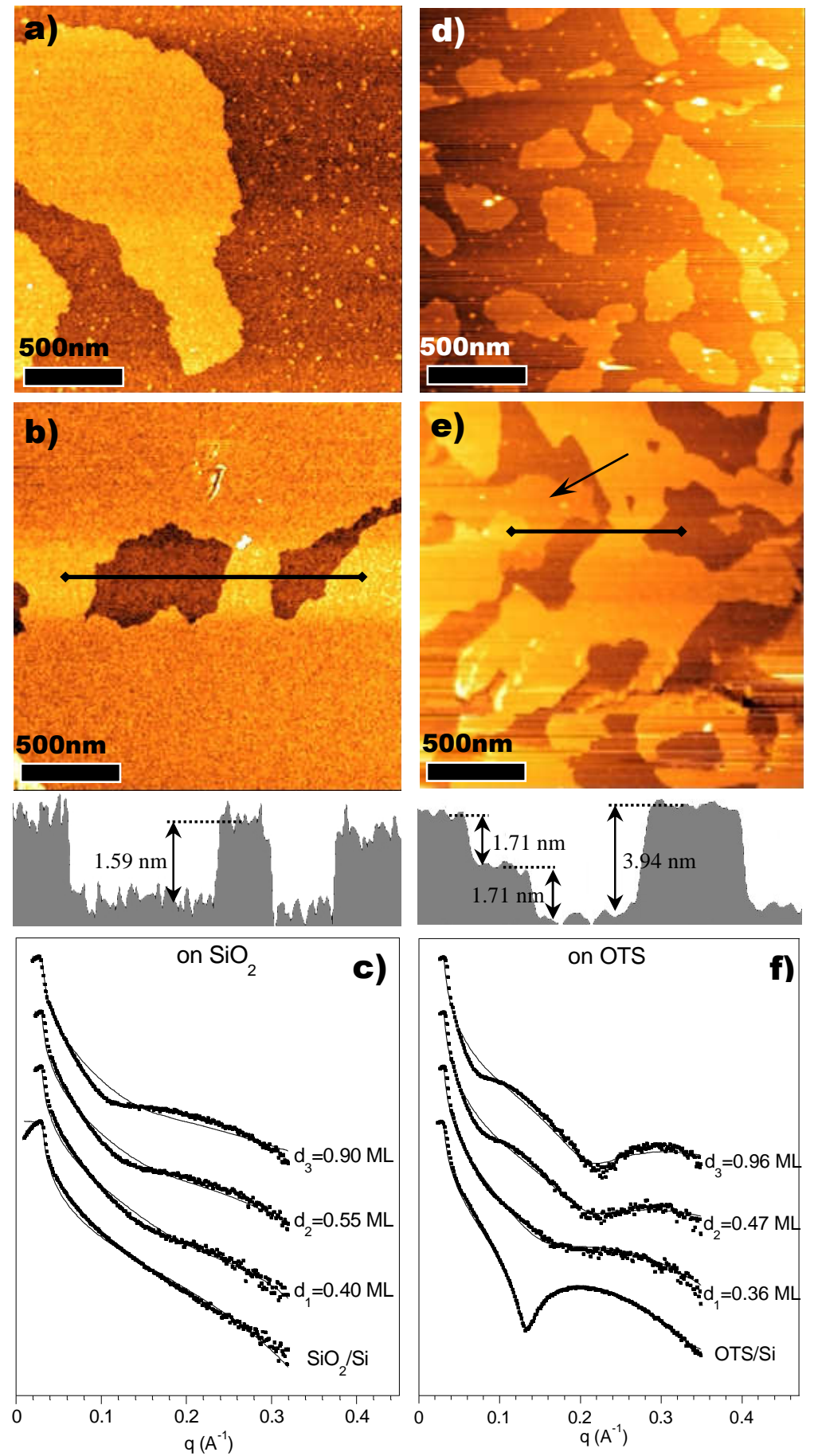

Figure 5: a)-c) $2 \times 2 \mu \mathrm{m}^{2} \mathrm{AFM}$ images of formation of the first PTCDI-5C monolayer at $120{ }^{\circ} \mathrm{C}$ on $\mathrm{SiO}_{2}$. a) $0.40 \mathrm{ML}$; b) $0.90 \mathrm{ML}$ with corresponding profile; c) X-ray reflectivity measurements. Experimental curves (symbols) and calculated curves (full line). d)-f) $2 \times 2 \mu \mathrm{m}^{2}$ AFM images of formation of the first PTCDI-5C monolayer at $120{ }^{\circ} \mathrm{C}$ on OTS. d) $0.36 \mathrm{ML}$; e) $0.96 \mathrm{ML}$ with corresponding profile; f) X-ray reflectivity measurements. 


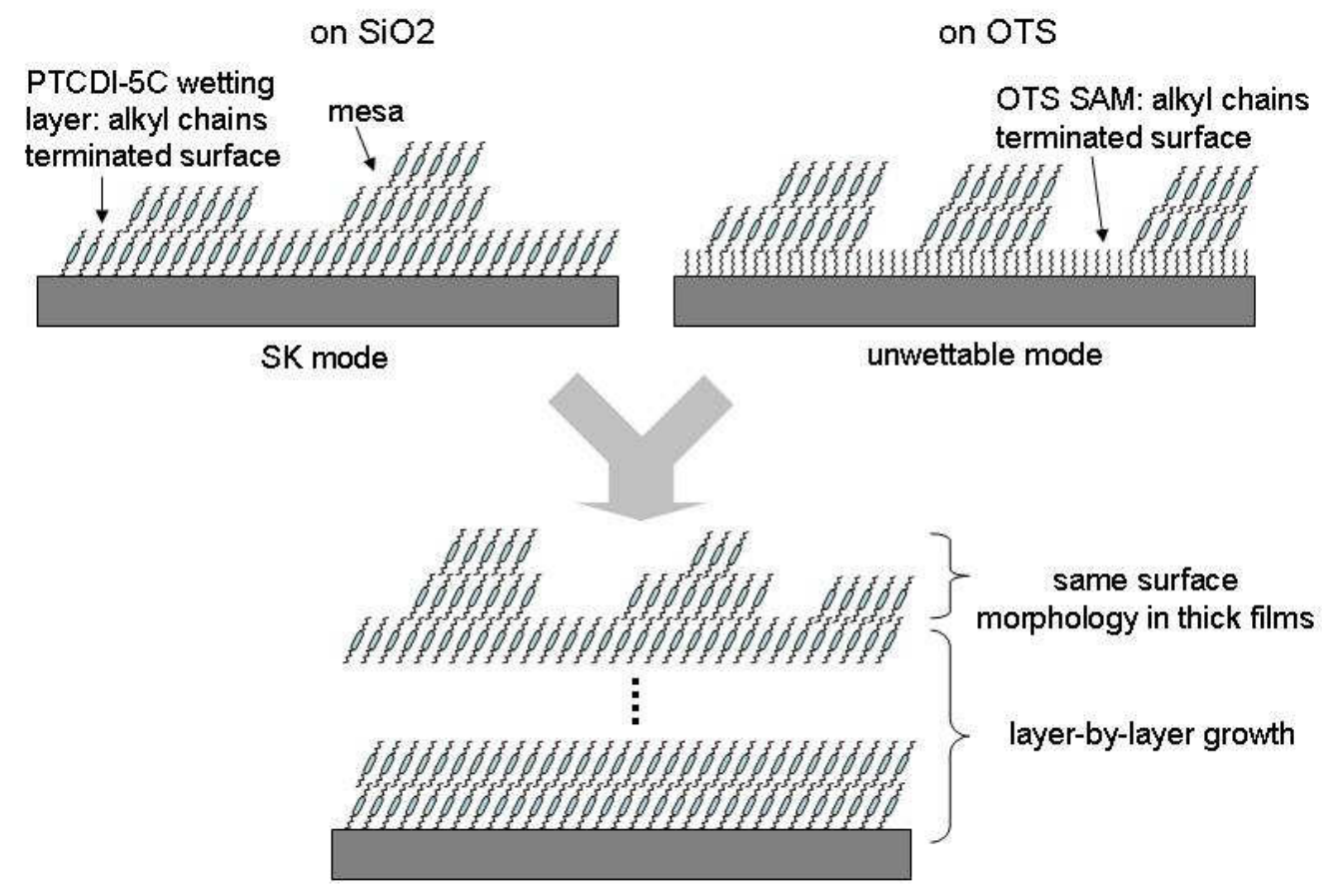

Figure 6: Scheme of the two different growth processes according to the nature of the substrate $\left(\mathrm{SiO}_{2}\right.$ or OTS). 


\begin{tabular}{l|l|lll}
\hline & & thickness film $\mathrm{d}_{1}$ & thickness film $\mathrm{d}_{2}$ & thickness film $\mathrm{d}_{3}$ \\
\hline \multirow{3}{*}{$\mathrm{On} \mathrm{SiO}_{2}$} & thickness $(\mathrm{nm})$ & 1.65 & 1.69 & 1.80 \\
& roughness $(\mathrm{nm})$ & 0.40 & 0.68 & 0.93 \\
& density $\left(\mathrm{g} . \mathrm{cm}^{-3}\right)$ & 0.80 & 0.88 & 1.33 \\
\hline \multirow{3}{*}{ On OTS } & thickness $(\mathrm{nm})$ & 1.66 & 2.70 & 2.80 \\
& roughness $(\mathrm{nm})$ & 0.65 & 1.02 & 1.99 \\
& density $\left(\mathrm{g} . \mathrm{cm}^{-3}\right)$ & 0.73 & $0.72-0.90$ & $1.00-1.39$
\end{tabular}

Table 1: Parameters used to fit the X-ray reflectivity curves. $\mathrm{d}_{1}=0.40 \mathrm{ML}, \mathrm{d}_{2}=0.55 \mathrm{ML}, \mathrm{d}_{3}=0.90$ ML for $\mathrm{SiO}_{2} ; \mathrm{d}_{1}=0.36 \mathrm{ML}, \mathrm{d}_{2}=0.47 \mathrm{ML}, \mathrm{d}_{3}=0.96 \mathrm{ML}$ for OTS. 